\title{
Buku Ajar Ekologi Komunitas Serangga Berbasis Problem-Based Learning untuk Mahasiswa
}

\author{
Danial Mursyd ${ }^{1}$, Suhadi $^{1}$, Fatchur Rohman ${ }^{1}$ \\ ${ }^{1}$ Pendidikan Biologi-Universitas Negeri Malang
}

\begin{tabular}{l} 
INFO ARTIKEL \\
\hline Riwayat Artikel: \\
Diterima: $25-06-2019$ \\
Disetujui: $14-02-2020$ \\
\hline
\end{tabular}

Kata kunci:

textbooks;

ecology;

problem based learning;

buku ajar

ekologi;

problem based learning

\begin{abstract}
The purpose of this development research is to produce a problem-based learning insects community ecology textbook that meet the requirements for validity and practicality. The development model used is the ADDIE model which consists of analyze, design, develop, implement, and evaluate. the primary data in this research obtained from validity questionnaires and practicality. The results of the research showed that the validation of material experts scored $93.33 \%$ with a very valid category. Validation from media experts showed a score of $95 \%$ with a very valid category. Validation from field practitioners gained a score of $75 \%$ with a practical category, and the results of trials from students obtained a score of $82.78 \%$ with a very practical category.
\end{abstract}

ABSTRAK

\begin{abstract}
Abstrak: Tujuan penelitian pengembangan ini adalah untuk menghasilkan buku ajar ekologi komunitas serangga berbasis problem-based learning yang memenuhi syarat kevalidan dan kepraktisan. Model pengembangan yang digunakan adalah model ADDIE yang terdiri dari analyze, design, develop, implement, and evaluate. Data primer dalam penelitian ini diperoleh dari angket validitas dan kepraktisan. Hasil penelitian menunjukkan bahwa validasi ahli materi mendapat nilai 93,33\% dengan kategori sangat valid. Validasi dari pakar media menunjukkan skor 95\% dengan kategori sangat valid. Validasi dari praktisi lapangan memperoleh skor $75 \%$ dengan kategori praktis, dan hasil uji coba dari siswa memperoleh skor 82,78\% dengan kategori sangat praktis.
\end{abstract}

\author{
Alamat Korespondensi: \\ Danial Mursyd \\ Pendidikan Biologi \\ Universitas Negeri Malang \\ Jalan Semarang 5 Malang \\ E-mail: mursyddania194@gmail.com
}

Pendidikan tinggi diselenggarakan dengan beberapa prinsip, salah satunya pembelajaran harus berpusat pada mahasiswa dengan memperhatikan lingkungan secara selaras dan seimbang (Undang-Undang Republik Indonesia No 12, 2012). Pemanfaatan lingkungan menjadi bahan pembelajaran merupakan modal bagi mahasiswa untuk bisa mengkonstruksi konsep secara (Abdul Kadir, 2013; Yenti, 2009) dengan menghubungkan konteks materi dengan dunia nyata (Santoso, 2017). Konteks materi pada matakuliah ekologi erat kaitannya dengan berbagai permasalahan lingkungan yang dekat dengan mahasiswa. Hal ini bisa dimanfaatkan di dalam pembelajaran untuk mencapai capaian pembelajaran yang sesuai dengan capaian pembelajaran matakuliah (RPS Ekologi UM, 2019) dan capaian standar lulusan untuk strata 1 yang telah tertuang di dalam KKNI (Permenristekdikti No 44, 2015).

Berdasarkan angket analisis kebutuhan yang dibagikan kepada mahasiswa Biologi Universitas Negeri Malang angkatan 2016 kelas A menyatakan bahwa pembelajaran ekologi sudah bersumber dari kejadian nyata, namun model pembelajaran yang digunakan pada topik kajian struktur komunitas adalah model pembelajaran kooperatif tipe Jigsaw. Hal ini membuat mahasiswa merasa model yang digunakan kurang sesuai. Berdasarkan wawancara dengan dosen ekologi, mahasiswa memerlukan pembelajaran yang dapat mengaitkan antara materi dengan contoh yang dekat dengan mahasiswa sehingga setiap mahasiswa diharapkan memiliki standar keilmuan yang sama.

Model pembelajaran yang dapat mengakomodasi konteks materi dan contoh yang dekat dengan mahasiswa adalah model pembelajaran problem based learning. Model pembelajaran problem based learning memfokuskan mahasiswa pada proses belajar dan bukan hanya sekedar hasil yang diperoleh (Rusmono, 2012). Hal ini bertujuan melatih cara berpikir lebih mendalam (Lidinillah, 2013) agar mahasiswa dapat mengkonstruksi konsep berdasarkan penyelesaian masalah yang ditemukan di lingkungan (Sani, 2014; Arends, 2012). Model problem based learning ini juga merupakan bagian dari student centered learning karena adanya perubahan paradigma seperti pengetahuan dipandang sebagai hasil konstruksi dengan cara belajar aktif dan spesifik serta dosen berpartisipasi bersama mahasiswa dalam membentuk pengetahuan (Arsika et al., 2016) optimalisasi penyelenggaraan prinsip student centered learning juga dipengaruhi oleh sumber belajar. Sumber belajar memiliki peran dalam 
mengubah paradigma bahwa dosen atau guru merupakan sumber informasi di kelas. Adanya sumber belajar berupa buku ajar, dosen lebih diarahkan menjadi fasilitator (Segoro, Sapto, \& Yuniastuti, 2019) yang membantu mahasiswa dalam mengontruksi konsep yang dipelajari (Sadjati, 2012).

Mahasiswa Biologi Universitas Negeri Malang angkatan 2016 kelas A telah menggunakan berbagai macam sumber belajar seperti buku ajar sebanyak 64\%, handout 8\%, modul 20\% dan selebihnya jurnal dan makalah. Mahasiswa juga menyatakan sumber belajar yang digunakan sulit untuk dipahami dan belum mengarahkan ke kehidupan nyata. Sumber belajar yang digunakan seharusnya sesuai dengan kebutuhan (Arifin \& Kusrianto, 2011) agar dapat mengembangkan pola penalaran yang runtut (Rahman, 2018). Hal ini dapat diatasi dengan mengembangkan sumber belajar berupa buku ajar yang sesuai dengan kebutuhan agar dapat meningkatkan rasa keingintahuan (Nurmita, 2017) dan meningkatkan hasil belajar (Anggela, Masril, \& Darvina, 2013; Barroh, Susantini, \& Ducha, 2012).

Berdasarkan latar belakang tersebut, perlu dilakukan penelitian pengembangan buku ajar ekologi komunitas berbasis problem based learning yang diperuntukkan untuk mahasiswa yang disusun berdasarkan kaidah buku teks dan digunakan sebagai acuan dan penyempurna dalam kegiatan pembelajaran (Hanifah, 2014; Tim Pengembangan Pembelajaran, 2015; Tim Penyusun LKPP, 2015).

\section{METODE}

Penelitian ini adalah penelitian pengembangan dengan menggunakan model pengembangan ADDIE. Model pengembangan $A D D I E$ dipilih karena memiliki karakteristik sederhana dan dapat dilakukan evaluasi untuk setiap tahapannya sehingga sesuai untuk mengembangkan produk pendidikan seperti buku ajar. Pada penelitian pengembangan ini hanya dilakukan empat tahapan dari lima tahapan yang ada. Tahapan pertama dari model pengembangan ini adalah analyze, pada tahap ini dilakukan pengumpulan informasi terkait permasalahan dan kebutuhan mahasiswa Strata 1 Pendidikan Biologi Universitas Negeri Malang. Tahap kedua design, pada tahap ini dilakukan penentuan komponen yang diperlukan dalam pengembangan buku ajar ekologi komunitas berbasis problem based learning. Tahapan ketiga Develop, pada tahap ini dilakukan pengembangan buku ajar dengan melakukan perancangan dan validasi oleh ahli materi, ahli media, praktisi lapangan dan respons mahasiswa (Branch, 2009). Data yang didapatkan berupa data kuantitatif yang diperoleh dari nilai validasi dan data kualitatif diperoleh dari masukan berupa saran dari validator dan mahasiswa. Teknik analisis data kuantitatif didapatkan dari rumus persentase (Akbar, 2013).

Data kevalidan buku ajar dari ahli materi dan ahli media menggunakan rumus persentase berikut.

$$
\text { Persentase } \%=\frac{\sum \text { skor jawaban }}{\sum \text { total skor maksimal }} \times 100 \%
$$

Data angket praktisi lapangan dan respons mahasiswa didapat dari skor yang diperoleh dari persentase dari rumus berikut.

$$
\text { Persentase } \%=\frac{\sum \text { skor jawaban }}{\sum \text { total skor maksimal }} \times 100 \%
$$

\section{HASIL}

Produk pengembangan yang dihasilkan adalah buku ajar ekologi komunitas berbasis problem based learning yang disusun berdasarkan kebutuhan mahasiswa dan pemanfaatan permasalahan di lingkungan terkait materi struktur komunitas. Pemanfaatan permasalahan menjadi bahan materi didalam buku ajar, diharapkan pembelajaran dapat berpusat pada mahasiswa sesuai dengan prinsip pendidikan tinggi. Buku ajar ekologi komunitas berbasis problem based learning ini telah melewati proses perbaikan berdasarkan validator ahli materi, ahli media, praktisi lapangan, dan respons mahasiswa. Data kevalidan dan kepraktisan buku ajar ini dijelaskan pada tabel 1.

Hasil validasi buku ajar struktur komunitas berbasis problem based learning oleh ahli materi diperoleh nilai rata-rata 93,33\%, ahli media diperoleh 95\%, dan ahli praktisi lapangan diperoleh 75\% Nilai yang diperoleh ini menunjukkan bahwa buku ajar struktur komunitas berbasis problem based learning layak digunakan didalam pembelajaran. Selanjutnya, dilakukan uji coba skala kecil kepada mahasiswa. Skor yang diperoleh dari uji coba skala kecil adalah 82,78\%. Validasi yang dilakukan juga memperoleh saran untuk perbaikan buku ajar ini. Saran perbaikan dijabarkan pada tabel 2. 
Tabel 1. Hasil Validasi dan Kepraktisan Buku Ajar Ekologi Komunitas Berbasis Problem Based Learning

\begin{tabular}{clll}
\hline Validator & Aspek & Persentase & \multicolumn{1}{c}{ Kategori } \\
\hline Ahli Materi & Relevansi & $94,44 \%$ & Pengembangan Buku Ajar Penulisan Artikel Jurnal \\
& Akurasi materi & $89,29 \%$ & Program Studi PBSI Program Magister \\
& Kemutakhiran & $93,75 \%$ & \\
& Penyajian & $95,83 \%$ & \\
\hline Ahli Media & Kelengkapan buku & $100 \%$ & Sangat Valid \\
& ajar & & Sangat Valid \\
\cline { 2 - 3 } & Cara penyajian & $100 \%$ & Sangat Valid \\
\cline { 2 - 3 } & Kesesuaian bahasa & $100 \%$ & Cukup Valid \\
\cline { 2 - 3 } & Keterbacaan dan & $75 \%$ & Sangat Valid \\
& Kekomunikatifan & & Praktis \\
\cline { 2 - 3 } & Kegrafisan & $100 \%$ & Praktis \\
\hline Ahli Praktisi Lapangan & Kemenarikan buku & $75 \%$ & Praktis \\
\cline { 2 - 3 } & Penyajian materi & $75 \%$ & Praktis \\
\cline { 2 - 3 } & Kemudahan & $75 \%$ & Sangat Praktis \\
& penggunaan & & $75 \%$ \\
\cline { 2 - 3 } & Manfaat & $82,78 \%$ & \\
\hline Uji Coba Kelompok Kecil (Mahasiswa) & Keterbacaan & \\
\hline
\end{tabular}

Tabel 2. Saran Perbaikan Buku Ajar Struktur Komunitas Berbasis Problem Based Learning

\begin{tabular}{cl}
\hline Validator & \multicolumn{1}{c}{ Aspek } \\
\hline Ahli Materi & $\begin{array}{c}\text { Sesuaikan hewan yang ada di TN Baluran untuk jejaring makanan, } \\
\text { Tambahkan gambar untuk rantai makanan } \\
\text { Perhatikan typo dalam penulisan } \\
\text { Tambahkan materi gangguan terhadap komunitas } \\
\text { Tambahkan contoh untuk materi interaksi }\end{array}$ \\
\hline Ahli Media & Belum tercetak bolak balik \\
& Gambar semut rangrang pada cover sebaiknya sebelah kanan \\
& Gambar peta kurang jelas sebaiknya dijadikan satu halaman dan di print laser \\
\hline Ahli Praktisi Lapangan & Masih banyak typo dalam penulisan \\
& Lihat susunan penulisan dari buku champbell \\
& Tambahkan gambar untuk rantai makanan \\
& Gambar peta agar lebih diperjelas \\
\hline Uji Coba Kelompok Kecil (Mahasiswa) & Perhatikan lagi penulisan karena masih ada typo \\
& Gambar agar lebih diperjelas \\
& Ditambahkan gambar serangga \\
\hline
\end{tabular}

\section{PEMBAHASAN}

Kualifikasi lulusan program sarjana diarahkan untuk dapat menguasai dasar ilmiah dan keterampilan sehingga dapat menemukan solusi dari permasalahan lingkungan sesuai bidang keahliannya (Ristekdikti, 2015). Dalam mewujudkan hal tersebut, mahasiswa perlu membiasakan diri dalam menyelesaikan permasalahan lingkungan. Pembelajaran problem based learning memberikan kesempatan kepada mahasiswa untuk mengintegrasikan pengetahuan dan keterampilan dalam menyelesaikan masalah (Sani, 2014). Dalam mendukung hal tersebut diperlukannya pengembangan sumber belajar berupa buku ajar berbasis problem based learning sebagai alternatif sumber belajar mahasiswa (Amri \& Ahmadi, 2010).

Pengembangan buku ajar ekologi komunitas berbasis problem based learning dilakukan agar dapat mengatasi permasalahan mahasiswa di dalam pembelajaran. Buku ajar ini disusun berdasarkan sintaks problem based learning. Pada kegiatan di dalam buku ajar, terdapat wacana atau masalah lingkungan terkait struktur komunitas yang sedang berkembang dan dekat dengan mahasiswa (Depari, Manurung, \& Sudibyo, 2016) sehingga dapat mendukung kompetensi yang akan dicapai (Newman \& Evans, 2004; Rusmono, 2012).

Validasi buku ajar ekologi komunitas berbasis problem based learning dilakukan oleh ahli materi dan ahli media. Hasil validasi oleh ahli materi diperoleh nilai rata-rata sebesar 93,33\% dengan kategori sangat valid. Kategori sangat valid juga diperoleh dari ahli media untuk setiap aspeknya dengan nilai rata-rata 95\%. Buku ajar ini juga dinilai oleh praktisi lapangan. Hasil kepraktisan oleh praktisi lapangan diperoleh kategori praktis dengan nilai rata-rata persentase $75 \%$. Hal ini dapat diartikan bahwa buku ajar dari setiap aspek yang dinilai telah layak digunakan dalam pembelajaran. Setelah dilakukan penilaian oleh ketiga ahli, dilakukan uji skala kecil kepada mahasiswa untuk keterbacaan, hasil yang diperoleh adalah 82,75\% dengan kategori sangat praktis. 
Hasil analisis buku ajar struktur komunitas berbasis problem based learning menunjukkan bahawa buku ajar ini telah sesuai dengan kurikulum (Achyani, Rustaman, Redjeki, \& Choesin, 2010) relevan dengan perkembangan (Leksono, Syachruroji, \& Marianingsih, 2015; Warsiman, 2014), sesuai dengan kebutuhan (Mustafa \& Efendi, 2016), menggunakan bahasa yang mudah dipahami (Sukiman, 2012), memiliki keharmonisan penggunaan warna (Depari et al., 2016; Sudjana, 2011), gambar yang bermakna (Daryanto, 2010; Rohani, 2017; Syari, Sumarmin, \& Ahda, 2013) dan memiliki keteraturan dalam penyajian (Majid, 2012). Hal ini memunculkan ketertarikan mahasiswa yang berdampak pada peningkatan aktivitas dalam menyelesaikan masalah lingkungan (Natalia., Lufri, \& Sumarmin, 2013), tercapainya capaian matakuliah (Hernawan, Permasih, \& Dewi, 2018; Tejo, 2011), dan mendukung peran dosen sebagai fasilitator (Syari., Sumarmin, \& Ahda, 2013).

Berdasarkan hasil validasi, kepraktisan, dan uji coba skala kecil yang telah dilakukan, buku ajar ekologi komunitas berbasis problem based learning layak digunakan di dalam pembelajaran. Buku ajar yang dihasilkan diharapkan dapat menjadi solusi bagi mahasiswa terhadap masalah terkait sumber belajar dan menjadi solusi untuk dapat mengembangkan kompetensi untuk tercapainya capaian matakuliah (Jailani \& Retnawati, 2016).

\section{SIMPULAN}

Buku ajar ekologi komunitas berbasis problem based learning disusun menggunakan model pengembangan ADDIE. Buku ajar ini layak digunakan didalam pembelajaran berdasarkan hasil validasi dari ahli materi dengan persentase nilai sebesar 93,33\% dengan kategori sangat valid, ahli media memperoleh kategori sangat valid dengan persentase nilai 95\%, praktisi lapangan memperoleh nilai persentase $75 \%$ dengan kategori praktis, dan uji skala kecil dengan memperoleh nilai persentase $82,75 \%$ dengan kategori sangat praktis.

Berdasarkan hasil penelitian pengembangan buku ajar ekologi komunitas berbasis problem based learning yang telah dilakukan, diharapkan adanya penelitian lanjutan untuk melihat keefektifan penggunaan buku ajar ini di dalam pembelajaran guna mengembangkan kompetensi untuk tercapainya matakuliah.

\section{DAFTAR RUJUKAN}

Achyani, A., Rustaman, N. Y., Redjeki, S., \& Choesin, D. N. (2010). Model Penulisan Buku Ajar Biologi SMA Berwawasan Ekologi dan Lokal untuk Meningkatkan Kepedulian Siswa terhadap Lingkungan. BIOEDUKASI (Jurnal Pendidikan Biologi), 1(1). https://doi.org/10.24127/bioedukasi.v1i1.180

Akbar, S. (2013). Pengembangan Kurikulum dan Pembelajaran Ilmu Pengetahuan Sosial. Yogyakarta: Cipta Media.

Amri, S., \& Ahmadi, I. K. (2010). Koleksi Buku 2010 Konstruksi Pengembangan Pembelajaran : Pengaruhnya terhadap Mekanisme dan Praktik Kurikulum. Jakarta: Prestasi Pustakaraya.

Anggela, M., Masril, \& Darvina, Y. (2013). Pengembangan Buku Ajar Bermuatan Nilai-Nilai Karakter pada Materi Usaha dan Momentum untuk Pembelajaran Fisika Siswa Kelas XI SMA. Pillar of Physics Education, 1(1), 63-70.

Arends, R. (2012). Learning to Teach. New York: Mc Graw-Hill.

Arifin, S., \& Kusrianto, A. (2011). Sukses Menulis Buku Ajar dan Referensi. Jakarta: Grasindo.

Arsika, I. M. B., Sudiarawan, K. A., Dharmawan, N. K. S., Samsithawrati, P. A., Widhyaastuti, I. G. A. D., \& Mahartayasa, M. (2016). Buku Pedoman Problem Based Learning (PBL). Denpasar: Unit Penjamin Mutu Fakultas Hukum Universitas Udayana.

Barroh, H., Susantini, E., \& Ducha, N. (2012). Pengembangan Buku Ajar Berjendela pada Materi Sistem Reproduksi Manusia untuk SMP RSBI. Bioedu, 1(2), 5-9.

Branch, R. (2009). Intructional Design: The ADDIE Approach. New York: Springer Science Buisinnes Media, LLC.

Daryanto. (2010). Media Pembelajaran. Bandung: Satu Nusa.

Depari, T. V., Manurung, B., \& Sudibyo, M. (2016). Pengembangan Buku Ajar Biologi Topik Ekologi Kelas VII SMP Berbasis Penemuan Terbimbing dengan Memanfaatkan Lingkungan Kebun Sayur. Jurnal Pendidikan Biologi, 6(1), $233-241$. https://doi.org/10.24114/jpb.v6i1.4326

Hanifah, U. (2014). Pentingnya Buku Ajar yang Berkualitas Pembelajaran Bahasa Arab. Jurnal At-Tajdid, 3(1), 99-121.

Jailani,. \& Retnawati, H. (2016). Keefektifan Pemanfaatan Perangkat Pembelajaran Berbasis Masalah untuk Meningkatkan HOTS dan Karakter Siswa. Jurnal Pendidikan dan Pembelajaran, 23(2), 111-123.

Kadir, A. (2013). Konsep Pembelajaran Kontekstual di Sekolah. Dinamika Ilmu, 13(3), 17-38.

Leksono, S. M., Syachruroji, A., \& Marianingsih, P. (2015). Development of Biology Conservation Teaching Materials Based on Ethnopedagogy. Jurnal Kependidikan, 45(2). https://doi.org/https://doi.org/10.21831/jk.v45i2.7494

Lidinillah, D. A. M. (2013). Pembelajaran Berbasis Masalah (Problem Based Learning). Jurnal Pendidikan Inovatif, 5(1), 1-7.

Majid, A. (2012). Perancangan Pembelajaran. Bandung: PT Remaja Rosdakarya.

Mustafa, D. A. I., \& Efendi, A. (2016). Pengembangan Bahan Ajar Pembelajaran Menulis Cerita Berbasis Pendekatan Proses bagi Siswa SMP. LingTera, 3(1), 1. https://doi.org/10.21831/lt.v3i1.8469

Natalia, D., Lufri, L., \& Sumarmin, R. (2013). Pengembangan Modul Pembelajaran Biologi Bermuatan Studi Kasus pada Materi Ekosistem untuk Siswa SMA/MA Kelas X. Kolaboratif, 2(1), 97-104. 
Newman, M., \& Evans, J. (2004). Problem Based Learning: An Exploration of the Method and Evaluation of its Effectiveness in a Continuing Nursing Education Programme . In Lifelong Learning. London: School of Lifelong Learning \& Education, Middlesex University.

Nurmita, F. (2017). Pengembangan Buku Ajar Siswa dan Buku Guru Berbasis Matematika Realistik untuk Meningkatkan Pengetahuan, Sikap dan Keterampilan Matematika Siswa Kelas VII SMP Al Karim Kota Bengkulu. EDU-MAT, 5(1), 8698.

Rahman, M. A. (2018). Pengembangan Buku Ajar Penulisan Artikel Jurnal Program Studi PBSI Program Magister

Ristekdikti. (2015). Paradigma Capaian Pembelajaran. Jakarta: Kemenristekdikti.

Rohani, A. (2017). Media Instruksional Edukatif. Jakarta: Rineka Cipta.

Rusmono. (2012). Strategi Pembelajaran dengan Problem Based Leaning itu perlu: Untuk Meningkatkan Professionalitas Guru. Bogor: Ghalia Indonesia.

Sadjati, I. M. (2012). Hakikat Bahan Ajar. In Pengembangan Bahan Ajar.

Sani, R. (2014). Pembelajaran Saintifik untuk Implementasi Kurikulum 2013. Jakarta: Bumi Aksara.

Santoso, E. (2017). Penggunan Model Pembelajaran Kontekstual untuk Meningkatkan Kemampuan Pemahaman Matematika Siswa Sekolah Dasar (Studi pada siswa kelas V SDN Sukarasa II Kecamatan Samarang Kabupaten Garut Tahun pelajaran 2014-2015 ). Jurnal Cakrawala Pendas, 3(1), 16-29.

Segoro, B., Sapto, A., \& Yuniastuti. (2019). Buku Ajar Tematik Berbasis Muatan Lokal untuk Kelas IV Sekolah Dasar. Jurnal Pendidikan: Teori, Penelitian, dan Pengembangan, 4(1), 1-5.

Setyawati, D. L., Rahayuningsih, M., Ahmad, T. A. (2013). Pengembangan Bahan Ajar Pendidikan Lingkungan Hidup Berkarakter di Universitas Negeri Semarang. Indonesian Journal of Conservation, 2(1), 33-44.

Sudjana, N. (2011). Penilaian Hasil Proses Belajar Mengajar. Bandung: PT Remaja Rosdakarya.

Sukiman. (2012). Pengembangan Media Pembelajaran. Yogyakarta: Pedagogja.

Syari, E. M., Sumarmin, R., \& Ahda, Y. (2013). Pengembangan Bahan Ajar Dilengkapi Video Pembelajaran dengan Pendekatan CTL pada Materi Organ Tubuh Manusia dan Hewan untuk Kelas V SD. Kolaboratif, 1(1), 13-21.

Tejo, N. (2011). Membuat Media Pembelajaran yang Menarik. Jurnal Ekonomi \& Pendidikan, 8(1), 19-35.

Warsiman. (2014). Kurikulum dan Masyarakat: Sebuah Korelasi yang Tak Terpisah.

Yenti, I. N. (2009). Pendekatan Kontekstual (CTL) dan Implikasinya dalam Pembelajaran Matematika. Ta'dib, 12(2), 118-125. 